\title{
Tooth Eruption and Browridge Formation
}

\author{
MARY DORIA RUSSELL \\ Department of Anthropology, University of Michigan, Ann Arbor, Michigan 48109
}

\author{
MILDRED TROTTER AWARD - 1980
}

\begin{abstract}
KEY WORDS Australian Aborigines, Browridge formation, Tooth eruption
\end{abstract}

\begin{abstract}
One of the most reasonable hypotheses regarding the functional significance of the browridge is that the supraorbital torus forms in response to masticatory stress during development. Oyen, Walker, and Rice (1979) have recently proposed a model that tests this hypothesis: if browridges are functionally related to masticatory stresses on the cranial vault, then changes in the biomechanics of the masticatory system ought to be reflected by changes in the browridge. To test their model they attempted to relate biomechanical discontinuities resulting from tooth eruption to episodes of bone deposition on the supraorbital tori of a developmental series of dry Papio crania. This paper reports on a parallel test of the model on a cross-sectional sample of Australian Aboriginal juvenile crania. This sample showed no relation between tooth eruption and the supraorbital surface morphology thought to be indicative of active bone deposition. It is also demonstrated that no significant relationship between tooth eruption and episodes of bone deposition is shown by the Papio sample. It is concluded that the use of small cross-sectional samples of dry crania does not provide a valid test of the model.
\end{abstract}

A number of authors have taken the view that external supraorbital torus morphology is significantly influenced by the biomechanical requirements of mastication (Toldt, 1914; Weidenreich, 1941; Washburn, 1947; Biegart, 1963; Enlow and McNamara, 1973; Oyen, Walker, and Rice, 1979; Oyen, Rice and Cannon, 1979). Experimental work by Endo (1966, 1970), Ehara $(1969,1972)$ and by Ehara and Seiler (1970) has provided evidence that portions of the primate supraorbital region are strained when forces are applied to the skull and anterior maxillary teeth in a manner simulating masticatory stresses. Endo's analysis (1966) indicated that the supraorbital torus acts as a beam that is subjected to bending moments generated by the downward and outward pull of the masseter and temporalis muscles and the upward force of the object being held between the teeth.

Oyen, Walker, and Rice (1979) recently proposed a developmental model that may be used to test the stress hypothesis of browridge formation: if primate supraorbital tori are functionally related to masticatory stresses on the cranial vault, as in vitro experiments suggest, then changes in the biomechanics of the masticatory system ought to be reflected by changes in the browridge. To test their model, they proposed that if browridges respond to mechanical stress, they should exhibit cyclic phases of growth reflecting discontinuous biomechanical changes associated with tooth eruption.

During facial growth, the anterior dentition moves downward and outward, away from the neurocranium and the masticatory muscles. Thus, adults require greater muscle effort to generate the vertical component of anterior bite forces equivalent to those achieved by younger, less prognathic individuals. That is, the biomechanical efficiency of the masticatory muscles decreases with age and consequently increased stresses may be transmitted to the supraorbital region during anterior dental loading (Oyen, Walker, and Rice, 1979).

Critical to the test of this model was the claim that the decrease in efficiency and increase in stress during growth is not gradual but sudden and cyclical, and that the cycle corresponds to the dental eruption cycle. According to Oyen, Walker, and Rice, in Papio, the eruption of a permanent molar results in a relatively sudden destabilization of the bio-

\footnotetext{
Received December 15, 1980; accepted September 14, 1981.
} 

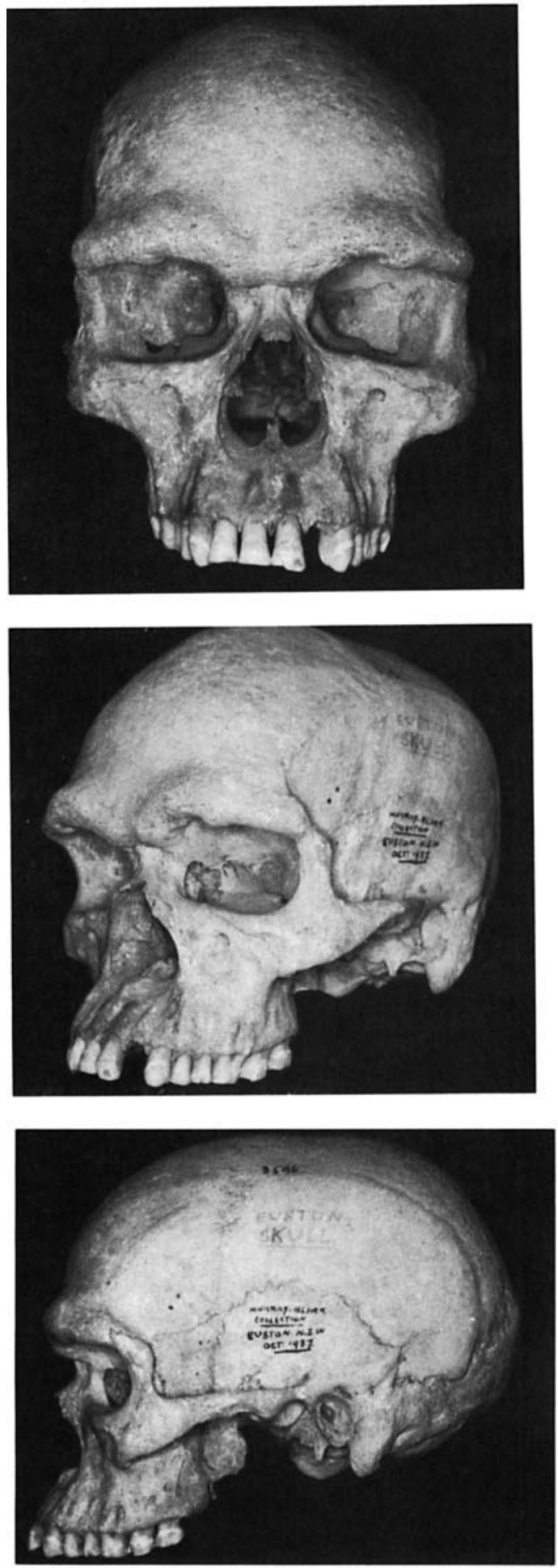

Fig. 1. A recent adult male Australian Aboriginal skull (Euston 3596) from the Murray Black Collection of the Australian Institute of Anatomy, Canberra, Australia. This individual demonstrates the robust supraorbital development and alveolar prognathism common among adult Aborigines. mechanical relationship between the masticatory muscles and the facial skeleton by changing the lever-arm:load-arm ratio of the jaws. During the period of molar eruption, they therefore expected a peak in the stresses transmitted to the browridge to trigger an episode of bone deposition. Oyen and his associates argued that the presence of a particularly fast growing type of bone, fine cancellous bone, could be used to infer that a region was undergoing a sudden increase in stress and therefore fine cancellous bone was an indicator of an episode of peak stress (Oyen, Walker, and Rice, 1979:174, 185).

They carried out a test of their model on a developmental series of 47 olive baboon crania (Papio anubis). Cross-sectional data resulting from their test was interpreted to mean that browridge formation in Papio proceeds discontinuously, by means of rapid deposition of fine cancellous bone, followed by periods of compaction. Further, they asserted that these episodes of fine cancellous bone deposition tend to coincide with the active eruption of teeth into the occlusal plane, as predicted by their model. They also believed that periods of bone remodeling and compaction begin when the teeth became functionally occlusive (Oyen, Walker, and Rice, 1979). These findings were later extended to explain browridge formation in macaques, chimpanzees, and Neandertals (Oyen, Rice, and Cannon, 1979).

Before the extension of this model to Neandertals can be justified, it is necessary to test it on a relatively large sample from an appropriate human population. For this reason, a parallel test of the Oyen, Walker, and Rice model of browridge formation was carried out on a sample of sub-adult Australian Aboriginal crania. Austalian Aborigines are appropriate subjects because they are one of the living human populations in which the adult supraorbital region is typically well-developed, with true supraorbital tori occurring in 2-3\% of the population (Larnach and Macintosh, 1966) (Fig. 1). Moreover, there is a large increase in prognathism during growth. Thus, the age related changes in masticatory biomechanics among Australian Aboriginal sub-adults seem to fit the model proposed by Oyen and associates.

In juvenile humans, the growing supraorbital region may be characterized by lamellar and parallel-fibered primary vascular bone forming as a very thin layer evenly applied to the underlying brow (Rice and Oyen, 1979). The model predicted that the occurrence and extent of primary vascular bone in the supraorbital region of Australian Aboriginal subadults should be temporally associated with 
changes in stresses accompanying the eruption of a permanent tooth. This parallels the claim that the model can be applied to Neandertals (Oyen, Rice, and Cannon, 1979).

\section{MATERIALS AND METHODS}

Crania used in this test were from the Murray Black collection of the Australian Institute of Anatomy in Canberra. The collection includes hundreds of recent Aboriginal skeletons exhumed by Dr. Murray Black and others (Sunderland and Ray, 1959). The juvenile crania used in this study were all from a region near the town of Euston on the Murray River in southeastern Australia.

All 49 sub-adult crania in the collection were examined and 43 were found to be complete enough for inclusion. The crania were seriated and aged following Wolpoff (1979). Individuals' ages ranged from approximately 3.5 to 18 years. Individuals were sorted into groups based on their dental eruption status. Following Oyen, Walker, and Rice (1979), the extent of the region of the surface morphology thought to be indicative of primary vascular bone on the frontal bone of each individual was measured. Finally, a chi-square test of independence was carried out to determine if there was an association between the extent of primary vascular bone and tooth eruption status.

The eruption status of each maxillary tooth was assessed as follows: (1) tooth crown in crypt; (2) tooth in alveolar eruption (a tooth was considered in eruption if the crown was visible beyond the level of the alveolus but not in occlusion); (3) tooth in occlusion (judged by the existence of polish or wear on the occlusal surface).

Following Oyen, Rice, and Cannon (1979) the crania were sorted into dental status groups defined as: (1) full deciduous dentition, $M 1$ in crypt; (2) M1 in eruption; (3) M1 in occlusion, I1, I2 in crypt; (4) incisors in eruption, M2 in crypt; (5) incisors in occlusion, M2 in crypt; (6) M2 in eruption; (7) M2 in occlusion; (8) M3 in eruption.

The extent of the regions of the frontal covered by primary vascular bone was then quantified. The surface morphology used to identify primary vascular bone was characterized as regions of the cortex that are perforated at right angles to the surface by shallow foramina; these foramina vary considerably in diameter and are seldom interconnected (Enlow, 1966; Rice and Oyen, 1979) (Fig. 2). Following Oyen, Walker, and Rice (1979), the areas of the frontal perforated by such foramina were covered with strips of transparent tape. The perimeter of the region of primary vascular bone was outlined on the tape. The marked tape was then transferred to paper and the areas were measured with a planimeter.

Deviating from the procedures used by Oyen, Walker, and Rice, in this test the $60 \%$ difference in frontal bone surface area between the youngest and oldest specimens was controlled for by expressing the area of primary vascular bone as a percentage of frontal bone area, which was approximated by multiplying the nasion-bregma chord times the bi-fronto-

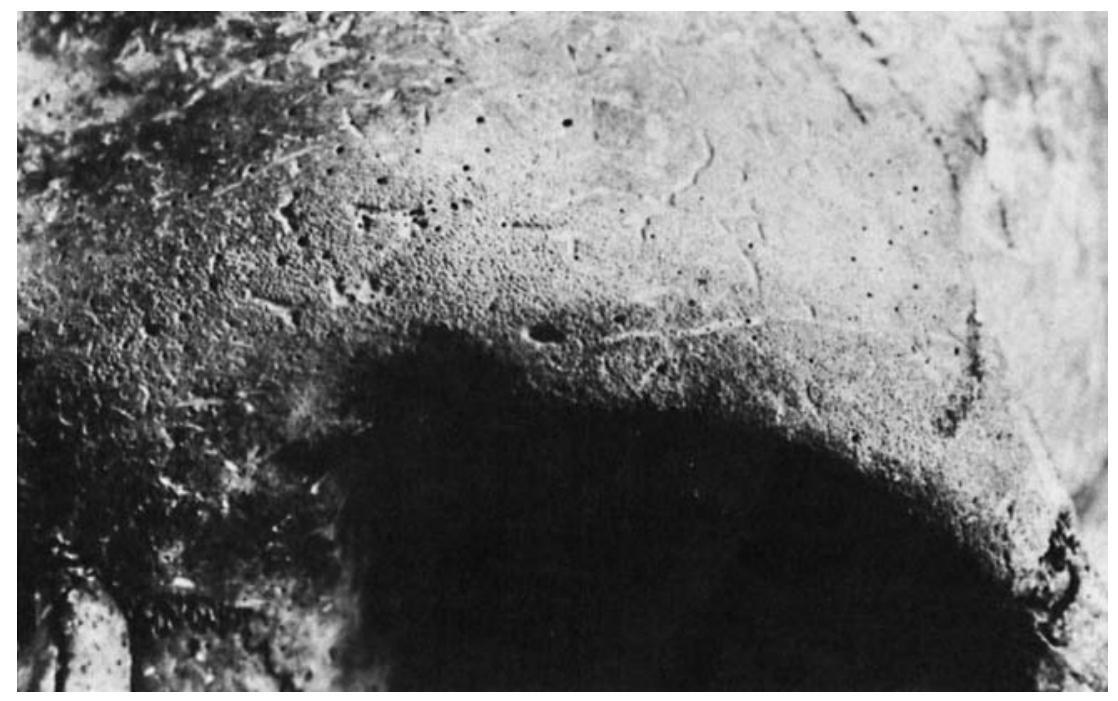

Fig. 2. The supraorbital region of this juvenile Australian Aboriginal cranium shows the surface morphology used to identify areas of primary vascular bone. It is cortical bone perforated at right angles to the surface by shallow for amina of various diameters, which are seldom interconnected. 
malartemporale frontal breadth. If $16 \%$ or more of a specimen's frontal was covered by primary vascular bone, the primary vascular bone was considered extensive. If $15.9 \%$ or less of the frontal was involved, the primary vascular bone was considered limited.

For the chi-square test for independence, the dental eruption status groups were then combined into two categories: (1) specimens with a tooth erupting (groups 2, 4, 6, and 8 above); and (2) specimens with no tooth erupting (groups 1, 3,5, and 7 above). This was justified because the model predicted that individuals with any tooth erupting should display extensive primary vascular bone in the supraorbital region and individuals with no tooth erupting should display more compacted bone in that region.

A two-by-two contingency table was constructed with the two dental eruption categories as the row variables and "limited" or "extensive" primary vascular bone as the column variables. For comparison, a similar contingency table was constructed in the manner described above for the Papio data reported by Oyen, Walker, and Rice (1979). Table 1 lists the data from which the contingency tables were constructed. Unfortunately, the sample sizes for macaques, chimpanzees, and Neandertals, the groups reported on in Oyen, Rice, and Cannon (1979), were too small to allow statistical analysis.

\section{RESULTS}

The chi-square test on the Aboriginal data showed the extent of primary vascular bone to be independent of dental eruption at the 0.05 level of significance (Table 2). Even when the eight dental eruption status categories were broken down and analyzed separately with respect to the extent of primary vascular bone, there was no individual tooth class that suggested a tendency to be associated with limited or extensive primary vascular bone. Furthermore, the occurrence of fine cancellous bone in Papio, reported in Oyen, Walker, and Rice (1979), was also independent of dental eruption status (Table 3 ). Thus, these tests provide no support for the notion that bone is more likely to be deposited on the supraorbital torus during or after periods of tooth eruption in either Australian Aborigines or Papio.

\section{DISCUSSION}

At the very least, these results indicate a number of ways in which the research design chosen by Oyen and his associates to test their model, and replicated here, seems to be inadequate.
First, as Oyen, Walker, and Rice (1979) themselves pointed out, cross-sectional samples can obscure or exaggerate developmental continuities and discontinuities. Individual differences in ontogeny can be misinterpreted as developmental stages and vice versa. This is particularly true in the analysis of small cross-sectional samples such as were necessarily relied on in these studies (Table 4).

Second, each of the parameters studied had considerable variation. Oyen, Walker, and Rice (1979) reported that in individuals of similar dental age, the extent of fine cancellous bone in Papio ranged from 0-9 $\mathrm{cm}^{2}$. Aboriginal subadult crania of virtually identical dental ages also differed widely in the proportion of the frontal bone covered by primary vascular bone. For example, two individuals with third molars in the same stage of eruption, AIA 3760 and AIA 3748 , displayed $51.4 \%$ and $8.1 \%$ primary vascular bone, respectively. Similarly individual, population, and species dental eruption schedules vary in sequence and elapsed time during episodes of eruption (Garn and Lewis, 1963; Swindler and McCoy, 1965).

Third, fine cancellous bone and primary vascular bone were necessarily identified using dry bone morphology, rather than wet tissue histological analysis. It is possible that the extent of fine cancellous bone and primary vascular bone was misrepresented in dry crania since the less mineralized components of immature bone matrix do not survive drying. Damage during burial and/or handling and cleaning of museum collection crania has almost certainly resulted in accidental removal of bone from the Australian crania and similar handling damage may also account for the large number of Papio specimens that displayed no fine cancellous bone. These factors may well have obscured any relationship between bone deposition and tooth eruption.

In addition, there are several aspects of the model itself that require refinement or modification. For example, the existence of a destabilized musculoskeletal relationship was initially inferred from the presence of fine cancellous bone and from the differences in leverarm:load-arm ratios in adult and juvenile baboon crania. Actually, Oyen and his associates only hypothesized that the presence of fine cancellous bone implies a growth spurt associated with biomechanical change (as opposed to histochemical changes, for example). Nor has a gradual change in lever-arm: load-arm ratios been ruled out by a longitudinal growth study.

Moreover, when longitudinal studies of lever-arm:load-arm changes are carried out, 
TABLE 1. Data from which the contingency tables were constructed ${ }^{1}$

\begin{tabular}{|c|c|c|c|c|c|c|}
\hline \multirow[b]{2}{*}{ Dental status } & \multicolumn{2}{|c|}{ Papio anubis } & \multicolumn{3}{|c|}{ Homo sapiens (Australian) } & \multirow[b]{2}{*}{$\begin{array}{c}\text { PVB area } \times 100 \\
\text { Frontal area }\end{array}$} \\
\hline & $\begin{array}{c}\text { Specimen } \\
\text { number }\end{array}$ & $\begin{array}{l}\mathrm{FCB}^{2} \\
\text { in } \mathrm{cm}^{2} \\
\end{array}$ & $\begin{array}{c}\text { Specimen } \\
\text { number }\end{array}$ & $\begin{array}{l}\mathrm{PVB}^{3} \\
\text { in } \mathrm{cm}^{2}\end{array}$ & $\begin{array}{l}\text { Frontal } \\
\text { area, } \mathrm{cm}^{2}\end{array}$ & \\
\hline \multirow{5}{*}{$\mathrm{dm}^{2}$ in occlusion } & 1 & 0 & 4093 & 0 & 72.5 & 0 \\
\hline & & & 3661 & 4.0 & 82.5 & 4.8 \\
\hline & & & 3626 & 2.7 & 79.2 & 3.4 \\
\hline & & & 4104 & 13.8 & 79.7 & 17.3 \\
\hline & & & 4098 & 14.6 & 86.0 & 17.0 \\
\hline \multirow[t]{5}{*}{$M^{1}$ erupting } & 2 & .52 & 4094 & 9.4 & 91.8 & 10.2 \\
\hline & 3 & 0 & 4103 & 7.8 & 95.0 & 8.2 \\
\hline & & & 3926 & 15.7 & 91.8 & 17.0 \\
\hline & & & 4100 & 11.2 & 82.5 & 13.6 \\
\hline & & & 3470 & 4.7 & 89.6 & 5.3 \\
\hline \multirow[t]{6}{*}{$M^{1}$ in occlusion } & 4 & 0 & 4095 & 3.5 & 92.7 & 3.8 \\
\hline & 5 & .77 & 3644 & 10.5 & 89.9 & 11.7 \\
\hline & 6 & 0 & & & & \\
\hline & 7 & 0 & & & & \\
\hline & 8 & 0 & & & & \\
\hline & 9 & 2.0 & & & & \\
\hline \multirow{6}{*}{ Incisors erupting } & & & L31 & 6.1 & 88.1 & 6.9 \\
\hline & & & 3663 & 14.3 & 93.1 & 15.4 \\
\hline & & & 4096 & 12.9 & 100.8 & 12.9 \\
\hline & & & L10 & 11.4 & 102.7 & 11.1 \\
\hline & & & L40 & 10.1 & 98.8 & 10.2 \\
\hline & & & 3570 & 9.8 & 93.9 & 10.4 \\
\hline \multirow[t]{8}{*}{ Incisors in occlusion } & & & 3651 & 9.8 & 93.9 & 10.4 \\
\hline & & & 3790 & 14.5 & 100.7 & 14.4 \\
\hline & & & 4097 & 16.1 & 104.2 & 15.5 \\
\hline & & & 3520 & 42.4 & 106.8 & 39.7 \\
\hline & & & 3534 & 8.6 & 102.0 & 8.4 \\
\hline & & & 3448 & 9.7 & 99.5 & 9.8 \\
\hline & & & 3653 & 4.4 & 111.2 & 4.0 \\
\hline & & & 3540 & 0 & 120.4 & 0 \\
\hline \multirow{12}{*}{$\mathbf{M}^{2}$ erupting } & 10 & 1.36 & 3444 & 27.3 & 111.5 & 24.5 \\
\hline & 13 & 0 & & & & \\
\hline & 15 & .95 & & & & \\
\hline & 16 & 1.59 & & & & \\
\hline & 20 & 0 & & & & \\
\hline & 21 & 0 & & & & \\
\hline & 11 & 3.07 & & & & \\
\hline & 12 & 0 & & & & \\
\hline & 14 & 3.3 & & & & \\
\hline & 17 & 0 & & & & \\
\hline & 18 & 1.36 & & & & \\
\hline & 19 & 0 & & & & \\
\hline \multirow{8}{*}{$M^{2}$ in occlusion } & 22 & 0 & 3882 & 47.6 & 110.1 & 43.2 \\
\hline & 24 & 0 & 3883 & 20.0 & 104.5 & 19.1 \\
\hline & 25 & 0 & 3924 & 18.7 & 96.6 & 19.4 \\
\hline & 23 & 2.9 & L8 8 & 25.1 & 95.0 & 26.4 \\
\hline & 26 & 0 & 4107 & 15.0 & 98.8 & 15.2 \\
\hline & & & ANU278 & 13.1 & 113.4 & 11.6 \\
\hline & & & $\mathrm{R} 2$ & 14.6 & 109.2 & 13.4 \\
\hline & & & 3472 & 14.9 & 105.3 & 14.2 \\
\hline \multirow[t]{10}{*}{$\mathbf{M}^{3}$ erupting } & 27 & 0 & 3483 & 42.9 & 116.1 & 37.0 \\
\hline & 28 & 0 & 3608 & 27.4 & 117.6 & 23.3 \\
\hline & 29 & 0 & 3760 & 53.5 & 104.0 & 51.4 \\
\hline & 30 & 0 & 3587 & 11.1 & 110.6 & 10.0 \\
\hline & 31 & 0 & 3748 & 9.6 & 118.8 & 8.1 \\
\hline & 32 & 0 & 3950 & 16.6 & 119.8 & 13.9 \\
\hline & 33 & 8.20 & & & & \\
\hline & 34 & 8.17 & & & & \\
\hline & 35 & 0 & & & & \\
\hline & 36 & 0 & & & & \\
\hline$M^{3}$ in occlusion & $37-47$ & 0 & & & & \\
\hline
\end{tabular}

I Papio data is from Oyen, Walker, and Rice, 1979.

${ }^{2}$ FCB: fine cancellous bone.

${ }^{3}$ PVB: primary vascular bone. 
TABLE 2. A two-by-two contingency test for independence of dental eruption status and the extent of primary vascular bone $(P V B)$ in the supraorbital region of Australian Aboriginal Juveniles

\begin{tabular}{lccc}
\hline \multirow{2}{*}{$\begin{array}{c}\text { Dental eruption } \\
\text { status }\end{array}$} & \multicolumn{2}{c}{$\begin{array}{c}\text { Percentage of frontal covered } \\
\text { by primary vascular bone }\end{array}$} & $\begin{array}{c}\text { Model } \\
\text { predicts }\end{array}$ \\
\hline Tboth erupting & $0-15.9 \%$ & $\geq 16 \%$ & $\begin{array}{c}\text { Should show } \\
\text { extensive PVB }\end{array}$ \\
\cline { 2 - 4 } No tooth erupting & Observed $=13$ & $\begin{array}{l}\text { Observed }=5 \\
\text { Expected }=5.27\end{array}$ & $\begin{array}{l}\text { Should show } \\
\text { less PVB }\end{array}$ \\
\hline
\end{tabular}

Null hypothesis must be rejected if chi square is greater than or equal to 3.841 (1 degree of freedom, 0.05 level of significance). Computed chi square $=0.03862$. Variables are independent.

TABLE 3. A two-by-two contingency test for independence of dental eruption status and the presence of fine cancellous bone $(F C B)$ in the supraorbital region of Olive Baboons ${ }^{1}$

\begin{tabular}{llll}
\hline \multirow{2}{*}{$\begin{array}{c}\text { Dental eruption } \\
\text { status }\end{array}$} & \multicolumn{1}{c}{ Individuals displaying } & Model predicts \\
\cline { 2 - 4 } Tooth erupting & \multicolumn{1}{c}{ no FCB } & some FCB & Should show extensive FCB \\
& $\begin{array}{l}\text { Observed }=15 \\
\text { Expected }=17.87\end{array}$ & $\begin{array}{l}\text { Observed }=9 \\
\text { Expected }=6.13\end{array}$ & Should show less FCB \\
& $\begin{array}{l}\text { Observed }=20 \\
\text { Expected }=17.12\end{array}$ & $\begin{array}{l}\text { Observed }=3 \\
\text { Expected }=3.69\end{array}$ & \\
\hline
\end{tabular}

${ }^{1}$ Constructed from data reported by Oyen, Walker, and Rice (1979).

Null hypothesis must be rejected if chi square is greater than or equal to 3.841 (1 degree of freedom, 0.05 level of significance). Computed chi square $=3.6922$. Variables are independent.

TABLE 4. Sample sizes used in Oyen, Walker, and Rice (1979), Oyen, Rice, and Cannon (1979), and in this study of the relationship between bone deposition in the supraorbital region and tooth eruption

\begin{tabular}{|c|c|c|c|c|c|}
\hline $\begin{array}{c}\text { Dental eruption } \\
\text { status }\end{array}$ & $\begin{array}{c}\text { Baboons } \\
\text { Oyen, Walker, } \\
\text { and Rice (1979) }\end{array}$ & $\begin{array}{c}\text { Macaques } \\
\text { Oyen, Rice, } \\
\text { and Cannon (1979) }\end{array}$ & $\begin{array}{c}\text { Chimpanzees } \\
\text { Oyen, Rice, } \\
\text { and Cannon (1979) }\end{array}$ & $\begin{array}{c}\text { Neandertals } \\
\text { Oyen, Rice, } \\
\text { and Cannon (1979) }\end{array}$ & $\begin{array}{l}\text { Aborigines } \\
\text { (this study) }\end{array}$ \\
\hline $\mathrm{dm}^{2}$ in occlusion & 2 & 0 & 1 & 1 & 6 \\
\hline $\mathrm{M}^{1}$ erupting & 3 & 1 & 1 & 0 & 5 \\
\hline $\mathrm{M}^{1}$ in occlusion & 6 & 2 & 2 & 1 & 2 \\
\hline$I^{1}$ erupting & 0 & 3 & 0 & 0 & 7 \\
\hline$I^{1}$ in occlusion & 0 & 0 & 0 & 0 & 8 \\
\hline $\mathbf{M}^{2}$ erupting & 12 & 4 & 2 & 0 & 1 \\
\hline $\mathbf{M}^{3}$ in occlusion & 5 & 5 & 2 & 0 & 8 \\
\hline $\mathrm{M}^{3}$ erupting & 10 & 0 & 1 & 0 & 6 \\
\hline $\mathrm{M}^{3}$ in occlusion (adult) & 11 & 5 & 8 & 7 & 0 \\
\hline
\end{tabular}

attention should be focused on the anterior dentition rather than the molars. According to Endo's biomechanical studies (1966) of the facial skeleton, molar loading primarily effects the pterygoid plates, not the supraorbital region. His work indicated that it is anterior tooth loading, particularly canine loading, which affects the supraorbital region most strongly. This suggests that it is the position of the anterior teeth relative to the masticatory muscles, rather than a tooth's eruption per se, which must show discontinuous change for the test of this model to be valid.

Even if the deposition of bone is eventually shown to be related to dental eruption, one must consider the possibility that bone deposition on one surface of the browridge may be matched by resorption on other surfaces such that the structure is merely translating during growth, rather than significantly changing its ability to resist stress. And, since it is the cross-sectional area of the supraorbital ridge and the cross-sectional distribution of its mass that can be expected to reflect changing stress vectors, these are the parameters that should be investigated in addition to studying the timing of bone deposition and resorption.

Finally, any model of browridge formation applicable to hominids must take into account a variety of behavioral factors that may 
exaggerate or obscure changes in the biomechanics of hominid masticatory anatomy. Barrett (1977) noted that the Walbiri Aborigines used their anterior teeth to hold stone axes while climbing trees, to sharpen wooden and stone implements, and for the various peeling, stripping, and gripping tasks involved in making bobbin spindles, digging sticks, and spears, etc. Since these activities are associated with economic adulthood, one might expect a sudden increase in stresses on the face to occur when individuals assume adult economic roles. This might or might not coincide with tooth eruption and could result in spurious results, unless controlled for.

In summary, a model has been proposed to test the hypothesis that the supraorbital torus forms in response to masticatory stresses during development. The model states that if browridges respond to mechanical stress, they should exhibit cyclic episodes of growth in response to biomechanical changes that presumably occur during tooth eruption. The first two tests of this model have not yielded results that support it but there is ample reason to believe that the use of small, cross-sectional samples of dry crania does not provide a valid test of the model, which itself needs modification. As Oyen, Walker, and Rice point out,

Longitudinal studies are needed. Measurements of maximum bite forces and assessments of muscle forces...should show if the biomechanical model has any validity. Experimental studies using strain gauges implanted on the circumorbital region might indicate whether there are sudden increases in certain mechanical stresses in that part of the skeleton. Associated histological studies might show whether...fine cancellous bone can be used to predict stress patterns (1979:185).

The Oyen, Walker, and Rice model can be used to generate a series of testable hypotheses. At this writing, all the lines of research mentioned above are being pursued and it seems likely that a consensus regarding the functional significance of primate browridges will soon be reached.

\section{ACKNOWLEDGMENTS}

The author would like to thank A.G. Thorne and the staff of the Australian National University Department of Prehistory (Research School of Pacific Studies) for their cooperation and assistance with materials used in this study. O.J. Oyen and A.C. Walker provided me with data and preprints of their research papers. Conversations with A.G. Thorne, P. Brown, C. Plumb, M.H. Wolpoff, O.J. Oyen, D. Carlson and D.J. Russell were helpful to me in clarifying the ideas and procedures employed in this paper. O.J. Oyen's helpful criticisms and encouragement were particularly appreciated. Comments from anonymous reviewers substantially improved this paper.

\section{LITERATURE CITED}

Barrett, MJ (1977) Masticatory and non-masticatory uses of the teeth. In RVS Wright (ed): Stone Tools as Cultura Markers: Change, Evolution, and Complexity, Canberra: Australian Institute for Aboriginal Studies.

Biegart, J (1963) The evaluation of characteristics of the skull, hands and feet for primate taxonomy. In SL Washburn (ed): Classification and Human Evolution, Chicago: Aldine.

Ehara, A (1969) Zur Phylogenese und Function des Orbitaseitrandes der Primaten. Z. Morph. Anthrop. 60:263-271.

Ehara, A (1972) Morphologische Analyse über variabilitat und Funktionelle Bedeutung det Jochbogen Form be: Kararrhinen Primaten. Z. Morph. Anthrop. 66:83-94

Ehara, A, and Seiler, R (1970) Die Struckturen der Überaugen region bei den Primaten, Deutungen und Definitionen. $\mathrm{Z}$ Morph. Anthrop. 62:1-29.

Endo, B (1966) Experimental studies on the mechanical significance of the form of the human facial skeleton. J. Fac. Sci. Univ. Tokyo, Section V, Anthropology 3:1-106.

Endo, B (1970) Analysis of stress around the orbit, due to masseter and temporalis muscles. J. Anth. Soc. Nippon 78:251-266.

Enlow, DH (1966) The evaluation of the use of bone histology in forensic medicine and anthropology. In FG Evans (ed): Studies on the Anatomy and Function of Bone and Joints. New York: Springer-Verlag, pp. 93-112.

Enlow, DH (1975) Handbook of Facial Growth. Philadelphia: Saunders.

Enlow, DH, and McNamara, R (1973) The neurocranial basis for facial form and pattern. Angle Orthodont. 43:256-270.

Garn, SM, and Lewis AB (1963) Phylogenetic and intra-spe cific variations in tooth sequence polymorphism. In DR Brothwell (ed): Dental Anthropology, Vol. 5, pp. 53-73.

Larnach, SL, and Macintosh, NWG (1966) Craniology of Aborigines of Coastal New South Wales. Oceania Monograph Number 13, University of Sydney.

Oyen, OJ, Rice, RW, and Cannon, SM (1979) Browridge structure and function in extant primates and Neanderthals. Am. J. Phys. Anthropol. 51:83-96.

Oyen, OJ, Walker, AC, and Rice, RW (1979) Craniofacial growth in olive baboons (P.c. anubis): browridge formation. Growth 43:174-187.

Rice, RW, and Oyen, OJ \{1979\} A morphogenetic analysis of primate browridge formation. Paper presented at the 49 th annual meeting American Association Physical Anthropologists, San Francisco.

Sunderland, S, and Ray, LJ (1959) A note on the Murray Black Collection of Australian Aboriginal skeletons. Proc. Roy. Soc. Vict. 71:45-48.

Swindler, DR, and McCoy, HA (1965) Primate Odontogenesis. J. Dent. Res. 44:283-295.

Tbldt, C (1914) Brauenwulste, Tbri supraorbitales, und Brauenbogen, Arcus supraciliares, und ihre mechanische Bedeutung. Mit. Anthrop. Ges. Wien 44:235-315.

Washburn, SL (1947) The relation of the temporal muscle to the form of the skull. Anat. Rec. 99:239-248.

Weidenreich, F (1941) The brain and its role in the phyloge netic transformation of the human skull. Trans. Am. Phil. Soc. 31:321-442.

Wolpoff, MH (1979) The Krapina dental remains. Am. J. Phys. Anthrop. 50:67-114. 